\title{
Signature of the Brazil-Malvinas confluence in the isotopic composition of planktonic foraminifera from core top sediments
}

\author{
Cristiano Mazur Chiessi ${ }^{1, *}$; Shannon Ulrich ${ }^{2}$; Stefan Mulitza ${ }^{1}$; \\ Jürgen Pätzold ${ }^{1} \&$ Gerold Wefer ${ }^{1}$ \\ ${ }^{1}$ Research Center Ocean Margins, University of Bremen, Postfach 330440, \\ 28334 - Bremen, Germany \\ chiessi@uni-bremen.de \\ ${ }^{*}$ CNPq-Brazil Research Fellow \\ ${ }^{2}$ Bryn Mawr College, Bryn Mawr, Pennsylvania, U.S.A.
}

The upper-level circulation in the southwestern Atlantic is dominated by the Brazil-Malvinas Confluence (BMC), that emerges from the encounter of southward-flowing warm, saline, and nutrient-depleted Brazil Current (BC) and northward-flowing cold, fresh, and nutrient-rich Malvinas Current (MC). At the junction both currents are deflected from the continental margin and flow south-eastward. Dramatically steep gradients in sea-surface temperature and sea-surface salinity are found in the confluence, reaching $1^{\circ} \mathrm{C} \mathrm{km}{ }^{-1}$. The BMC migrates north and south seasonally, lying farther south during austral summer than during the winter. This oscillation is triggered by the change in transport of both the $\mathrm{BC}$ and the MC.

The main factors controlling calcite oxygen isotope composition $\left(\ddot{a}^{18} \mathrm{O}_{c}\right)$ of planktonic foraminifera are the temperature and the isotopic composition of the water in which calcification takes place, both factors being biased to some extent by the species specific vital effects. Nevertheless, ä of planktonic foraminifera records the temperature, latitudinal temperature gradient, and stratification of upper-water masses and has the potential to deliver important information about past environments.

We measured the $\mathrm{a}^{18} \mathrm{O}$ of planktonic foraminifera from a latitudinal transect of core tops from the continental slope off Brazil, Uruguay, and Argentina between 20 and $49^{\circ} S$ to test its potential use as a proxy for the position of the BMC. The species measured cover a wide range of water depths, comprising surface dwellers like G. ruber (pink) and G. sacculifer, subsurface species like G. bulloides, and deep dwellers like G. truncatulinoides (dextral) and G. inflata. 
The lowest values of ${ }^{18} \mathrm{O}_{c}$ are found for G. ruber (pink) and $G$. sacculifer, in which the latter show slightly higher values than the former. The shallow water low $\ddot{a}^{18} \mathrm{O}$ anomaly characteristic of the Rio de la Plata outflow is registered just on the $\ddot{a}^{18} \mathrm{O}_{c}$ of $G$. ruber (pink). The $\ddot{a}^{18} \mathrm{O}_{c}$ values of the other three species were considerably higher, and the values of ${ }^{c} G$. bulloides and $G$. inflata show a strong decrease associated with the BMC. These are the only species available across the confluence. $\mathrm{a}^{18} \mathrm{O}_{c}$ values of $G$. truncatulinoides (dextral) are available north of the BMC where they are remarkably stable.

Our data associated to the biogeographical distribution of the species measured show that $G$. ruber and G. sacculifer reflect surface water conditions north of the BMC, whereas G. truncatulinoides (dextral), G. bulloides, and G. inflata reflect subsurface conditions north (e.g. G. truncatulinoides dextral), and south (e.g. G. bulloides, G. inflata) of the confluence. The combination of G. truncatulinoides (dextral) and G. inflata turned out to be the most reliable indicator for the position of the BMC and can therefore be used to define the past migration of the front. 